\title{
Bringing an Emphasis on Technical Writing to a Freshman Course in Electrical Engineering
}

\author{
John E. Mahan, Anura Jayasumana, Senior Member, IEEE, Derek Lile, Senior Member, IEEE, and Mike Palmquist
}

\begin{abstract}
We have recently added a strong writing component to one of our freshman courses in electrical engineering. The students prepared two kinds of reports-memoranda and formal engineering project reports. Our instructional objectives were to execute well these two forms: to write with a professional tone, and to make good choices about which technical material to include. To meet these objectives, model memos and engineering project reports were developed, lectures about these memos and reports were presented, a Web site for the course was developed, the technical aspects of the reports were graded by a student hourly grader, the writing aspects of the reports were evaluated by a professor, and followup debriefings were conducted at the lecture class meetings. We report on the development process and discuss student response to the course.
\end{abstract}

Index Terms-Electrical engineering education, engineering writing, freshman, project report, technical reports, technical writing, writing.

\section{INTRODUCTION}

W E HAVE recently added a strong component on writing to one of our freshman courses in electrical engineering, EE102 Digital Circuit Logic. Our decision to add a writing emphasis is based on the recognition that our undergraduates must be able not only to apply their technical knowledge to work in electrical engineering but also to effectively communicate, in writing, the results of their work.

Much of the incentive for improving the communication skills of our graduates comes from industry [1]-[4]. Since industry is the ultimate employer of many of our engineering graduates, we should try to meet this need by maintaining a curriculum that trains our students to produce good technical writing.

To gain a better understanding of industry perceptions of the communications skills of recent graduates in electrical engineering, we polled the representatives to the industrial advisory board for our academic department [5]. The respondents were unanimous in their opinion that engineering college graduates typically have poor skills in both writing and oral presentation. Specific problems they identified include:

- an inability to clearly present ideas;

- an inability to describe the reason for a communication;

- an inability to link five or six sentences into a coordinated, logical paragraph;

Manuscript received January 4, 1999; revised October 18, 1999.

J. E. Mahan, A. Jayasumana and D. Lile are with the Department of Electrical Engineering, Colorado State University, Fort Collins, CO 80523-1373 USA

M. Palmquist is with the English Department, Colorado State University, Fort

Collins, CO 80523-1373 USA.

Publisher Item Identifier S 0018-9359(00)01449-7.
- production of long, rambling reports that lack a clear introduction, summary, or purpose statement;

- excessive use of jargon, buzz words, and acronyms, particularly in electronic communications.

Our board told us they would like us to place more emphasis on preparing our students for the writing tasks they will experience in the workplace, including:

- writing a one page executive summary that gets to the heart of the issue;

- writing a business letter that can be understood by a secretary;

- writing a concise technical paper;

- spelling correctly and following standard grammar and mechanics.

Our industrial partners told us that the accelerated use of e-mail in the workplace had reinforced the need to provide our graduates with effective writing skills. Finally, two of our industrial partners commented on the poor oral presentation skills they had observed in conference settings. Although this might be viewed as primarily a weakness in public speaking rather than technical writing, writing ability affects a presentation through preparation of good visual aids and the composition of a logical, to-the-point talk. These findings are consistent with earlier research on the communication practices in a large high technology company that routinely hires our graduates [6], [7].

Over the past decades, training in engineering writing has not been a well-developed part of our own curriculum, nor of those of our sister departments. Although published reports of curriculum efforts to integrate communication skills into the engineering curriculum have begun appearing [8]-[13], it has not been, frankly, an active area for engineering educators. Another hindrance is that integration of writing instruction into the curriculum has been viewed as a type of training that is excessively costly to deliver. This present effort to respond to the above concerns was, as a result, a home-grown and untried solution. Each component was novel: defining for the first time our writing skills objectives, implementing these in the undergraduate curriculum, and accomplishing this at acceptable cost in terms of faculty time and other resource usage. One of the most fruitful steps was to establish a collaboration with writing specialists in the English department of our University.

Our first undertaking, the subject of this article, was to add a writing skills emphasis to assignments which previously had been graded mainly for technical content. In our EE102 class, the students complete ten design projects and prepare ten written reports of their work. With this new initiative, we now focus on 
what these reports should accomplish as communication vehicles, grading the reports on this basis as well as on technical content.

We tried to make the reporting as realistic as possible. The students were encouraged to place themselves in the position of working engineers reporting to their supervisors and colleagues, rather than of students writing for their professor. In addition, we supported writing instruction in the course through use of a Web site containing the details of the writing assignments, e-mail links to tutors in our University Writing Center, and links to information about writing which is available on the Writing Center Web site (see the URL's of these two Web sites in Section VI).

The purpose of this article is to describe how we did it, and to relate what we learned about teaching these writing skills to freshman engineers as part of the laboratory component of this freshman course. Through this initiative we gained specific knowledge of the students' initial inability to prepare acceptable reports, and yet saw the development of basic competence across essentially the entire class of 92 students by the end of the semester.

\section{TeChNical Writing ObJectives}

The instructional objectives for the report writing were:

- to execute well two forms of reporting, the memorandum and the formal engineering project report;

- to write with a professional tone;

- to make good choices about which technical material to include.

These are the skills we focused on, and all of the instructional components were developed to meet these ends.

\section{DEFINING THE Two REPORT Formats}

The students prepared reports in two forms. The first four project reports were prepared as memoranda, and the next five reports were formal engineering project reports. (The tenth report was the special "frazzled boss report" which included simply the technical work without text. This relaxation of the writing requirement was a "gift" to the students at the end of a long, hard semester.)

A memorandum was defined for them as a brief and factual document having the following characteristics: It is a message to a colleague or supervisor within the author's organization. The textual part often serves as a cover statement for attached material. The reader may choose only to read the memo itself, or may go on to examine the attachments; thus, the students were requested to include equations, circuit diagrams, plots, etc., as attachments. In most cases, a satisfactory memorandum text fits onto a single page.

The formal engineering report is not so brief. In our course, it had five distinct parts, with technical material, such as equations, circuit diagrams, and plots, integrated into the text, rather than attached at the end. The parts are:

- cover page;

- problem statement;

- analysis and design;
- summary and conclusions;

- Appendix.

In contrast to the memo, the project report was conceived as an integrated document where the details are not attachments, but rather are blended into the narrative. A typical engineering report for this class was 6-12 pages long.

\section{REQUIRED CONTENT}

The required content of the memos was:

- a statement of the purpose of the project;

- a description of their analysis and design work;

- a summary of the results;

- equations, circuit schematics, and logic timing diagrams as attached figures;

- concluding statements as to whether the work was successful, and what the student found to be keys to success in completing the project.

The required content of the formal engineering project reports consisted of the same general sections. However, because of the greater length of the reports, we provided detailed instructions concerning technical material that was to be included in each section.

The problem statement was always to contain a specific statement of purpose, as well as any constraints that were imposed on their circuit design. The analysis and design section was to be a narrative presentation of the work they did, with equations, figures, and text integrated. We specified which equations and derivations should be included, and what the subject of each figure should be. The summary and conclusions were to begin with a statement of whether their designs were successful-that is, whether their computer simulations exhibited the requested behavior, and whether their actual hardware circuits behaved properly. The second part of the summary and conclusions was to be a brief statement of things they found to be keys to success in completing the project, or approaches by which the problem might best be solved. The Appendix was a place to respond to specific technical questions which had been posed in the assignment. (We soon realized that answering homework-type questions is not a part of a real design project, and it will not be included in the reports in future semesters.)

\section{Writing With a Professional Tone}

There are many aspects to writing with a professional tone, but we focused on just two:

- use of a word processor and computer graphics (there was to be no handwriting anywhere in the document);

- to write as a working professional to a colleague or supervisor, rather than as student to instructor.

To prepare the report with computer and printer is reasonable because, like most of our sister departments, we provide computers and software for their use. Writing with a word processor is simply fundamental to establishing a professional tone.

To write from the viewpoint of a working professional was almost entirely new to them. It meant at least three things in this context: 1) to focus on the work itself instead of what one learns or experiences, 2) to play the role 


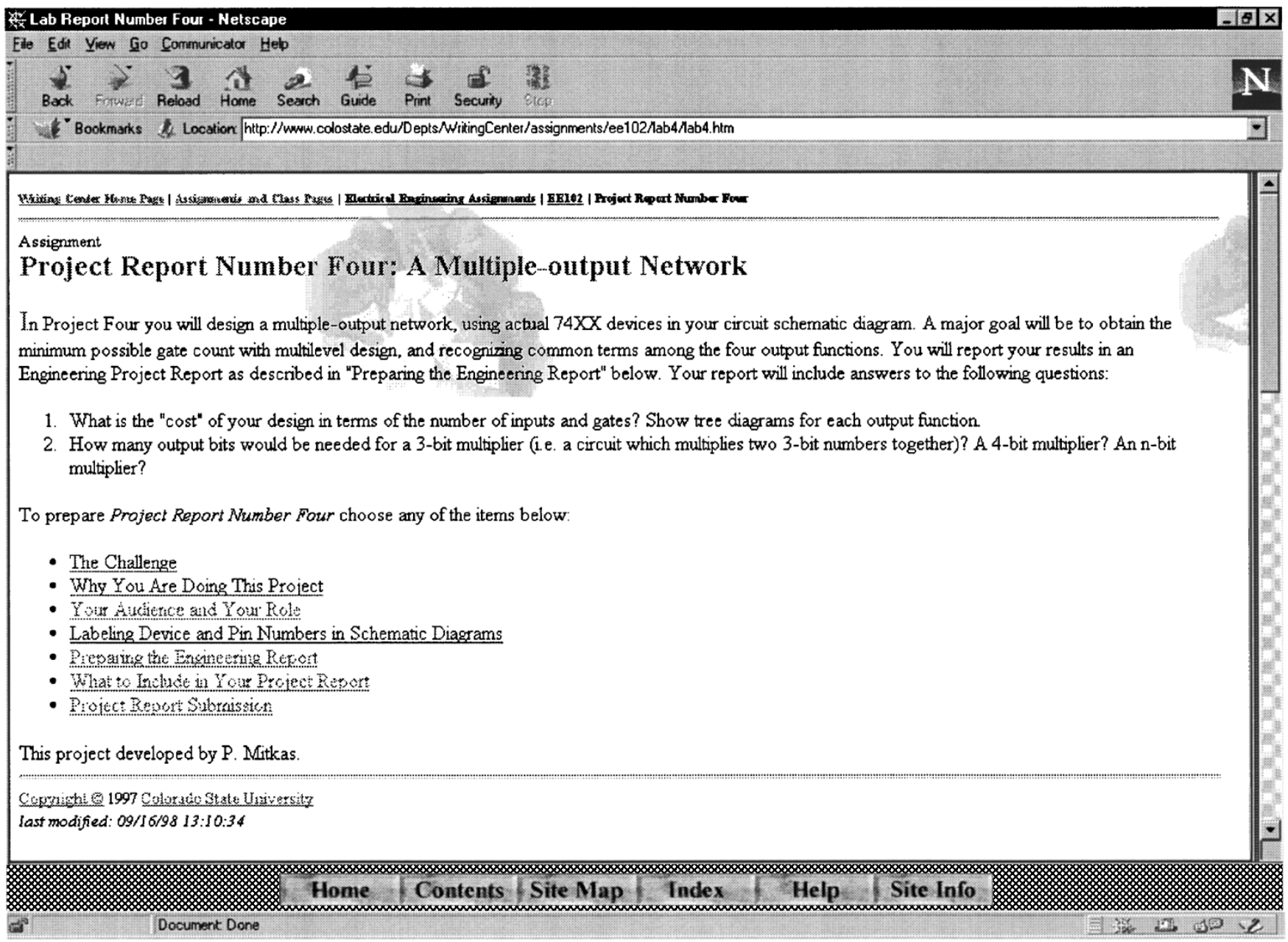

Fig. 1. Web page serving as an introduction to Project \#4.

of a professional engineer, rather than an engineering student in a class, and 3) to consider one's audience to be a colleague or supervisor, rather than a professor. To focus on one's experiences means to say things like "I learned a lot about flip-flops in this lab." To help them play the role of a professional, we created imaginative situations for them, such as suggesting that they are tail-light engineers at Rolls-Royce. Frequently, they framed their reports while playing these roles, making comments such as, "My first assignment as tail-light engineer was to design ...," which then established their professional stance for the rest of the report. In writing for the professor (inappropriately), one might say "the purpose of this project was to introduce us to timing diagrams." We uncovered other basic principles of writing with a professional tone but chose not to emphasize them in the course, preferring to stick to the two just detailed. These other principles are mentioned in the Appendix of this article.

\section{IMPLEMENTATION}

The following instructional elements were developed for the course:

- a model memo and a model engineering project report;
- Lecture presentations on what the two types of reports should be, and accomplish;

- a written challenge for each project, posing the technical problem the students were to solve with their circuit designs;

- an internet Web site for the course (which may be viewed at http://www.colostate.edu/Depts/WritingCenter/assignments/ee102/ee102.htm);

- grading of the technical aspects of their reports by a paid student grader;

- grading of the writing aspects of their reports by a professor;

- follow up debriefings on the success of their reports, presented to the class of 92 students at the lecture class meeting.

Our definition of the memo was itself conveyed to the students in the form of a memo, which served as an example of the desired typesetting format. In addition, we gave them an engineering project report as an example of that typesetting format; the subject of the model report was what a report should contain, in general terms.

The lecture presentations included motivational discussions about the importance of good technical writing, and explanations of the general nature of memos and engineering project 


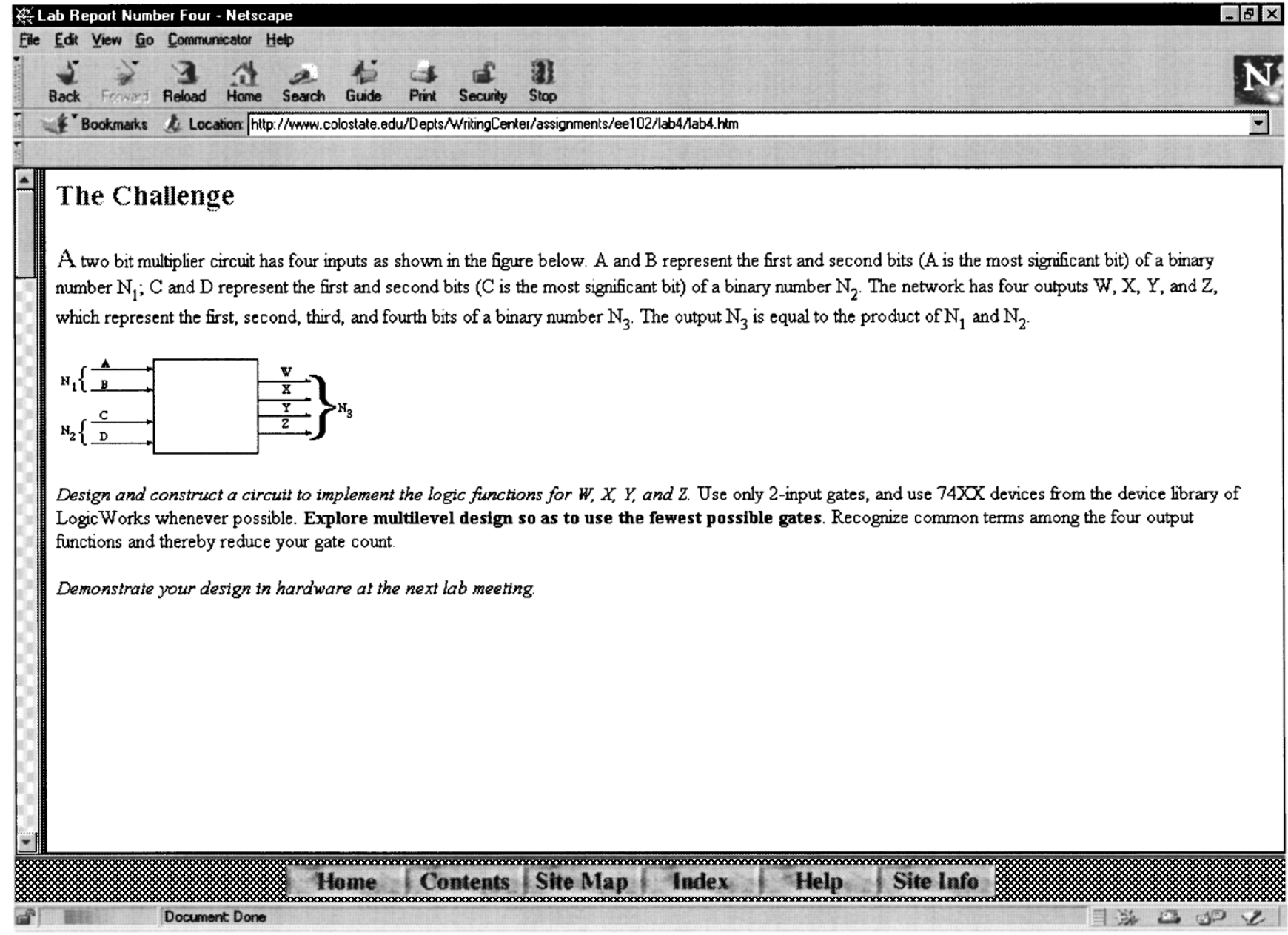

Fig. 2. Web page giving the technical "Challenge" for Project \#4.

reports. We encouraged them to write as professionals by discussing audience, and giving them roles to play. For example, in the rather preliminary Project \#0, Banana Electronics' Slippery Logic Division has just received a new software package. A staff engineer (the student) is asked to verify that the software works correctly and report this in a memo to the supervisor. In Project \#6 the student is the principal electrical engineer on the Starship Enterprise, and must build an "electronic identifier" using a multiplexer chip. A full engineering project report for the captain is required.

In the laboratory class meeting, the students received a written challenge, which posed the problem they were to solve with their circuit designs. Each challenge contained a list of the required content of the report, along with the following statement: "Go to the class homepage (Internet Web site) for EE102 for instructions on preparing your report."

A class Web site was constructed, with a page (see Fig. 1 for an example) for each project. These Web pages repeated the challenge (see Fig. 2), and provided background information and detailed instructions for preparing the report (see Fig. 3). These instructions included:

- Why You Are Doing This Project

(stating learning goals pertaining to both technical knowledge and writing skills);
- Your Audience and Your Role (reminding them to write as a professional, and what that means);

- A Point of Technical Information (depending on the project);

- Preparing the Engineering Report (repeating our definition of the report type, with the model report);

- What to Include in Your Project Report (specific technical material that is required);

- Project Report Submission

(a reminder of the due date, time, and place).

The class Web site was developed within a larger writingacross-the-curriculum initiative at Colorado State University. This initiative provides online support for writing instruction (http://www.colostate.edu/Depts/WC/) in a variety of courses at Colorado State University [14], [15].

The grading of the technical content of their report was accomplished using a paid student hourly grader. Grading of the writing aspects of the reports, as well as general administration of the laboratory, was done by a professor. This professor's assignment was considered equivalent to the teaching of one class for workload purposes. The writing was graded on a most basic level. Was the typesetting format of the report followed? Was 


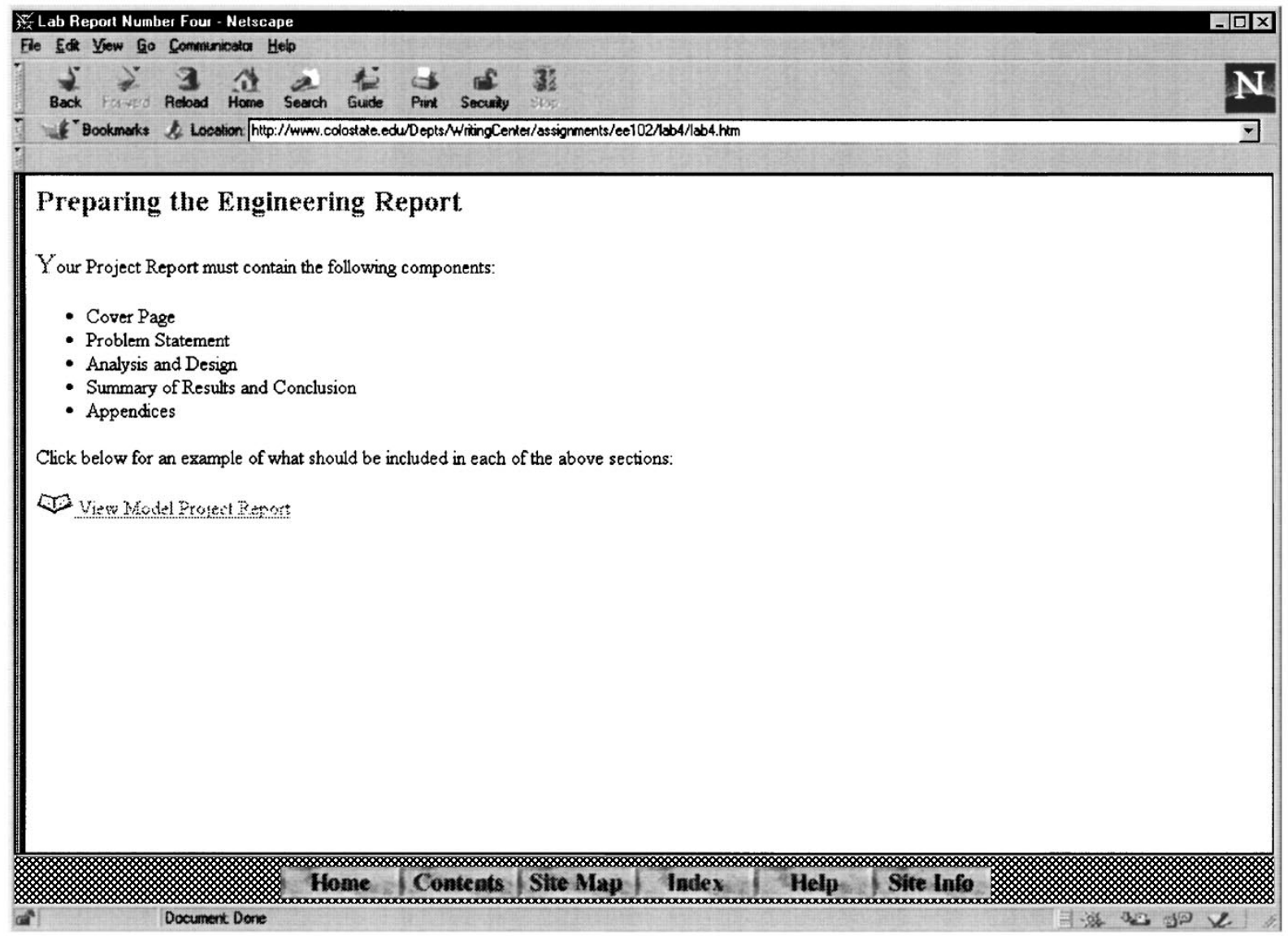

Fig. 3. Web page on "Preparing the Engineering Report."

the required content present in each section and basically understandable? Thus, nonnative English writers suffered no penalty for their relatively awkward and unconventional constructions, so long as they were communicating the required message. This approach helped speed up the grading and allowed foreign students to experience success while at the same time helping them gain a more mature command of English. Proofreading errors were noted, but were not penalized.

After all the reports of a given project were graded, we debriefed the class at a lecture meeting. This included a summary of their scores on various aspects of the reports, and examples of both successful, and unsuccessful writing. One of the most frequently repeated admonitions was, "Don't say this. Remember you are writing as a professional, not a student!"

\section{CONCLUSIONS AND PlanS}

We polled the students during the last week of the semester in order to probe their attitudes toward this emphasis on technical report writing (their responses were anonymous). 83\% affirmed that "it is a good idea to emphasize technical report writing as we did in this class." We interpret this overwhelmingly positive response from students as an indication that the students understood the importance of developing their writing skills, and were willing to spend extra effort toward attaining this. The students who responded negatively to our question felt that the writing skills, if they are important, should be taught in a class on technical writing, that there was too much emphasis on writing, or that it demanded too much of their time. We believe as educators that we must strive for integration, and minimize compartmentalization, of the knowledge and skills they receive during their college years.

We explored electronic (paperless) reporting but found it unsatisfactory. The printed paper document seems to be irreplaceable for communicating substantial engineering work, especially when graphics are combined with text and the document is several pages in size.

The success of this approach depends heavily on both the technical knowledge of the instructor(s), and on the their dedication to writing excellence. A typical electrical engineering graduate teaching assistant lacks the experience and motivation required to execute this program. Similarly, the typical graduate assistant in a "communications" major, such as technical writing, does not have the technical knowledge necessary to grade the reports. Thus, our course involved two Professors in Electrical Engineering, one teaching the usual technical material, and the second concentrating on the writing portion of the course. The teaching load for each Professor was considered equivalent to that of teaching one course.

We believe that it is critical to focus on writing skills in the first laboratory course the freshmen take within our department. This allows us to establish, early on, our high expectations with respect to report writing for all the engineering classes. We do 
believe that it will be important to follow up with a writing emphasis in subsequent courses. Mandating these formats in every lab class would reinforce their memo- and report-writing skills, but will require additional resources that are difficult to afford. Frankly, not every faculty member attaches the same importance to writing. Thus, instead of duplicating this approach in every course, we plan to follow up by emphasizing writing in one laboratory course at the junior level.

\section{APPENDIX}

In grading the 900 or so reports during the semester, certain other principles of writing with a professional tone emerged. These included the following.

- Avoid excessive expressions of personal feelings and experiences.

"Amazingly, my hardware circuit went well, and it worked on my first try at the power source: I was so very pleased I almost did cartwheels down the hall ...." (Such enthusiasm was gratifying but had to be discouraged in the written reports.)

- Avoid inexact or imprecise statements.

"This lab again utilized the concepts of encoding." ("Concepts of encoding," whatever that means, was not part of the technical language of the course.)

- Avoid disorganized or inconvenient formatting.

A frequent example was continuing a table from the bottom of one page to the top of the next page.

- Proofread for typographical and spelling errors, and inconsistent format.

These principles were not emphasized in the course, because we wanted to keep the message simple and make sure certain other basic things were accomplished.

\section{REFERENCES}

[1] K. N. Black, "An industry view of engineering education," J. Eng. Educ., vol. 83, no. 1, pp. 26-28, 1994.

[2] F. W. Garry, "A business look at engineering education," Eng. Educ., vol. 77 , no. 4, pp. 203-205, 1986.

[3] J. D. Lang and J. H. McMasters, "Enhancing engineering and manufacturing education: Industry needs, industry roles," in Amer. Soc. Eng. Educ. Conf. Exposition, 1995.

[4] W. H. Middendorf, "Academic programs and industrial needs," Eng. Educ., vol. 71, no. 8, pp. 835-837, 1980.

[5] D. L. Lile, private communication.

[6] D. Vest, M. Long, L. H. Thomas, and M. E. Palmquist, "Relating communication training to workplace requirements: The perspective of new engineers," IEEE Trans. Prof. Commun., vol. 38.1, pp. 1-7, 1995.

[7] L. H. Thomas, "Educating electrical engineers for workplace communication: A qualitative study," Master's thesis, Colorado State University, 1994.

[8] R. Baren, "Teaching writing in required undergraduate engineering courses: A materials course example," J. Eng. Educ., vol. 82, no. 1, pp. 59-61, 1993.

[9] P. Beebe, "Skill with words: A new emphasis in the education of Cornell engineers," Eng.: Cornell Quarterly, vol. 24, no. 3, pp. 20-25, 1990

[10] A. W. Fentiman and J. T. Demel, "Teaching students to document a design project and present the results," J. Eng. Educ., vol. 84, no. 4, pp. 329-334, 1995.

[11] S. Hawkins, M. B. Coney, and K.-E. Bystrom, "Incidental writing in the engineering classroom," J. Eng. Educ., vol. 85, no. 1, pp. 27-34, 1996.

[12] S. Manual-Dupont, "Writing-across-the-curriculum in an engineering program," J. Eng. Educ., vol. 85, no. 1, pp. 35-40, 1996.
[13] K. H. Schulz and D. K. Ludlow, "Incorporating group writing instruction in engineering courses," J. Eng. Educ., vol. 85, no. 3, pp. 227-232, 1996.

[14] M. Palmquist, D. Rodrigues, K. Kiefer, and D. Zimmerman, "Enhancing the audience for writing across the curriculum: Housing WAC in a network-supported writing center," Comput. Composition, vol. 12, pp. 335-353, 1995.

[15] M. Palmquist, K. Kiefer, and D. E. Zimmerman, "Creating community through communication across the curriculum," in Electronic Communication Across the Curriculum, D. Reiss, D. Selfe, and A. Young, Eds. Urbana, IL: National Council of Teachers of English, 1998.

John E. Mahan received the B.S. degree in engineering sciences from Purdue University, West Lafayette, IN, in 1970 and the doctorate degree in materials science and engineering in 1976 from Stanford University, Stanford, CA.

After completing the doctorate, he investigated photovoltaic devices as a Research Associate at the Massachusetts Institute of Technology. He has also spent sabbatical years at the Center for Research on the Mechanisms of Crystal Growth in Marseille, France, and at the Institute for Nuclear and Radiation Physics at the Catholic University of Leuven, Belgium. He is currently Professor of Electrical and Computer Engineering at Colorado State University, offering graduate courses in physical vapor deposition, and thin film growth. His scholarly interests include thin films, epitaxial growth, physical vapor deposition methods, semiconducting silicide materials, effective teaching methods, and today's college student. His first book is Physical Vapor Deposition of Thin Films (New York: Wiley, 2000).

Anura Jayasumana (S'83-S'85-SM'90) received the B.Sc. degree in electronics and telecommunication engineering, with first class honors, from the University of Sri Lanka, Moratuwa, in 1978. He received the Ph.D. degree in 1985 and the M.S. degree in 1982, both in electrical engineering from the Michigan State University, East Lansing.

$\mathrm{He}$ is a Professor in the Electrical and Computer Engineering Department and the Computer Science Department, at the Colorado State University. His research interests include high-speed network protocols, performance evaluation, and VLSI design and testing. He has authored/coauthored more than 130 publications in these areas and a book "FDDI and FDDI-II: Architecture, Protocols and Performance," published by Artech House.

Dr. Jayasumana has served as a consultant to industry, an Associate Editor of the IEEE Network, and as the General Chair and the Program Chair of the IEEE International Workshops on IDDQ Testing. He is a member of Phi Kappa Phi, the IEEE Computer Society, and the IEEE Communications Society. He was the winner of the award for the best student in electrical engineering at the University of Sri Lanka, Moratuwa, in 1978, and the College of Engineering Outstanding Academic Achievement Awards at Michigan State University in 1982 and 1983. He received the Outstanding Faculty of the Year Award from the Mountain States Council of the American Electronics Association in 1990, and Engineering Deans Council Award for Academic Excellence from the Colorado State University in 1998

Derek Lile (M'87-SM'97) received the B.Sc. degree with first class honors and the M.Sc. degree, both from the University of Wales, in electrical engineering, in 1964 and 1965, respectively. In 1998, he earned the Ph.D. and D.I.C. degrees from Imperial College, London.

He worked at the Naval Ocean Systems Center in San Diego directing a research group in the area of high-speed semiconductor devices. He is currently Professor and Head of the Electrical and Computer Engineering Department at Colorado State University. At Colorado State University his research interests have included materials growth and characterization, and electric and optoelectronic device development. He has published more than 60 journal papers and three book chapters. He has served on numerous conference organizing committees, has chaired a variety of conference sessions, and has presented invited papers at many conferences.

Dr. Lille received the Lauritzen-Bennett Award for Excellence in Science in 1979, the Engineering Dean's Council Award for Academic Excellence in 1987, and the Jack E. Cermak Outstanding Adivsor's Award in 1992. He is a member of Tau Beta Phi. In 1990, he was a Fulbright Scholar Recipient of a Senior Lecturer Award to the Ecole Centrale de Lyon. 
Mike Palmquist is an Associate Professor of English at Colorado State University, where he codirects the Center for Research on Writing and Communication Technologies. His scholarly interests include writing across the curriculum, the effects of computer and network technologies on writing instruction, and the use of hypertext/hypermedia in instructional settings. His work has appeared in journals including Computers and Composition, Written Communication, IEEE

TRANSACTIONS ON PROFESSIONAL COMMUNICATION, Journal of Engineering Education, Kairos, Council of College Teachers of English Studies, and Social Forces, as well as in edited collections. He is coauthor of Transitions: Teaching Writing in Computer-Supported and Traditional Classrooms (Norwood, NJ: Ablex, 1998) and coauthor of Writing with a Computer (Boston, MA: Allyn and Bacon, 1999). 